\title{
Türkçe Öğretmeni Adaylarının Osmanlı Türkçesi Dersine Yönelik Öğrenen Güçlenmesi Düzeyleri*
}

\section{Learner Empowerment Levels of Pre-Service Turkish Teachers Towards Ottoman Turkish Course}

\author{
Dr. Ahmet BAŞKAN ${ }^{(1)}{ }_{1}$, Dr. Öğr. Üyesi Hatice ALTUNKAYA ${ }^{(D}{ }_{2}$
}

\begin{abstract}
$\ddot{O} \mathbf{z}$
Bu çalışmada, Türkçe öğretmeni adaylarının Osmanlı Türkçesi dersine yönelik öğrenen güçlenmesi düzeyleri cinsiyet ve sınıf değiş̧enleri açısından incelenmiştir. Araştırma, 2017-2018 eğitim-öğretim yılının bahar döneminde Dicle Üniversitesi Ziya Gökalp Eğitim Fakültesi Türkçe Eğitimi Ana Bilim Dalı'nda öğrenim gören toplam 167 öğrencinin katılımı ile gerçekleştirilmiş̧tir. Araştırmada, katılımcıların Osmanlı Türkçesi dersine yönelik öğrenen güçlenmesi düzeylerinin belirlenmesi amacıyla Frymier, Shulman ve Houser (1996) tarafından geliştirilen, Çakır ve Erdoğan (2014) tarafından Türkçeye uyarlanan "Öğrenen Güçlenmesi Ölçeği" kullanılmıştır. Araştırma sonucunda, cinsiyet ve sınıf değişkenleri açısından öğretmen adaylarının öğrenen güçlenmesi düzeylerinin "etki", "anlamlllık" ve "yeterlilik" boyutlarına göre istatistiksel açıdan anlamlı düzeyde farklılık göstermediği belirlenmiştir. Elde edilen bulgular sonucunda Türkçe öğretmeni adaylarının Osmanlı Türkçesi dersinde yapacakları faaliyetleri belirleyebildiği ve derste takdir edildikleri, Osmanlı Türkçesi dersinde edindikleri bilgileri ve yerine getirmeleri gereken görevleri anlamlı buldukları, Osmanlı Türkçesi dersi ile ilgili görevleri layıkıyla yerine getirebilme konusunda kendilerine güvendikleri, bu derste başarılı olmak için gerekli niteliklere sahip olduklarını düşündükleri sonucuna ulaşılmıştır.
\end{abstract}

Anahtar Kelimeler: Öğrenen güçlenmesi, Osmanlı Türkçesi dersi, Türkçe öğretmeni adayı

Makale Türü: Araştırma

\begin{abstract}
In this study, learner empowerment levels of pre-service Turkish teachers towards Ottoman Turkish course was examined in terms of gender and class variables. The research was conducted with the participation of a total of 167 students studying at the Department of Turkish Language Teaching at Ziya Gökalp Education Faculty of Dicle University in the spring semester of 2017-2018 academic year. In the study, "Learner Empowerment Scale" developed by Frymier, Shulman and Houser (1996) and adapted to Turkish by Çakır and Erdoğan (2014) was used in order to determine the level of learner empowerment for the Ottoman Turkish course. As a result of the research, it was determined that the level of the learner empowerment in terms of gender and class variables did not differ statistically according to the dimensions of "impact", "significance" and "adequacy". As a result of the findings, it is found that preservice Turkish teachers are able to determine the activities they will perform in the Ottoman Turkish course and they are appreciated, they find task meaningful in the course and fulfill the tasks they need to fulfill; they are confident in fulfilling their duties related to the Ottoman Turkish course and the qualities they have achieved.
\end{abstract}

Keywords: Learner empowerment, Ottoman Turkish course, pre-service Turkish teachers

Paper Type: Research

\footnotetext{
* Bu çalışma 13-15 Eylül 2018 tarihleri arasında Aydın Adnan Menderes Üniversitesi’nde düzenlenen II. Uluslararası Eğitim Araştırmaları ve Öğretmen Eğitimi Kongresi’nde sözlü bildiri olarak sunulmuştur.

${ }^{1}$ Dicle Üniversitesi, Ziya Gökalp Eğitim Fakültesi, ahmet.baskan@ dicle.edu.tr.

${ }^{2}$ Aydın Adnan Menderes Üniversitesi, Eğitim Fakültesi, hatice.altunkaya@ adu.edu.tr.
}

Atıf için (to cite): Başkan, A. ve Altunkaya, H. (2019). Türkçe Öğretmeni Adaylarının Osmanlı Türkçesi Dersine Yönelik Öğrenen Güçlenmesi Düzeyleri. Afyon Kocatepe Üniversitesi Sosyal Bilimler Dergisi, 21 (3), 808-815. 


\section{Giriş}

Son yıllarda, okullardaki program geliştirme ve uygulamalarına ilişkin gerçekleştirilen dönüşümler ve bu dönüşümlerin eğitim sürecine yansımaları ile birlikte öğrenci merkezli öğrenme yaklaşımı benimsenmiştir. Bu yaklaşım, ilköğretimden üniversiteye tüm kademelerde öğreneni pasif bir alıcıdan aktif hâle getirmeyi içeren uygulamaları ve kavramları da beraberinde getirmiş̧ir (Çakır ve Erdoğan, 2014). Bu kavramlardan biri de "öğrenen güçlenmesi” kavramıdır.

Öğretmen ve öğrenciler, öğrenmeyi kolaylaştıran yollarla iletişim kurdukları için sosyal etkiyi birlikte ele alırlar. Ancak, bu süreçlerin meydana geldiği mekanizmalar büyük ölçüde incelenmeden kalmaya devam eder. Öğretmen gücünün öğretim çıktıları üzerindeki etkilerini potansiyel olarak değiştirebilecek etmenlerden biri de öğrenen güçlenmesidir (Schrodt ve diğerleri, 2008).

Çalışma hayatında, yönetici-çalışan ilişkileri ile ilgili çalışmalardan (Block, 1987; Senge, 1990) eğitim alanına geçen güçlenme (empowerment) kavramı, kişinin bir işi tamamlamada, bir görevi yerine getirmede içsel bir motivasyon oluşturma sürecini ifade eder (Thomas ve Velthouse, 1990). Öğrenen güçlenmesi, motivasyon temelli bir yap1 olarak kavramsallaşmıştır, bu da öğrenci ilgisi ile pozitif ilişkilidir (Weber ve Peterson, 2000; Frymier ve diğerleri, 1996; Thomas ve Velthouse, 1990).

Conger and Kanungo (1988) öğrenen güçlenmesi kavramının kişilerin çalıştıkları ortamdaki verimliliklerini artıran faydalı bütünsel bir his olduğunu belirtir. Zimmerman'ın (1990: 73) ifadesiyle, "öğrenen güçlenme düzeyleri yüksek bireyler, yaşamları üzerinde kontrol ve ustalık kazanırlar ve karşılaştıkları sorunları çözmek için bu becerilerden faydalanırlar". Luechauer ve Shulman (1993) ise, öğrenen güçlenmesi kavramının öğreten ve öğrenen arasındaki hedeflere ulaşmada önemli bir rol oynadığını ifade eder.

Öğrenen güçlenmesi, öğrencilerin olumlu tutumlarının veya içsel motivasyonlarının artmasından fazlasını ifade eder. Çünkü kişisel katılımın ve öz yeterliliğin bilişsel bir inanç durumunu içerdiği için öğrenciler arasında kişisel etkililik duygusunun artmasıyla sonuçlanır (Schrodt ve diğerleri, 2008: 184).

Öğrenen güçlenmesi, kişilerin motivasyon ve başarılarını artırır. Öğrenen güçlenme düzeyleri yüksek olan öğrenciler, sınıf görevlerini yerine getirmek için daha fazla motive olurlar, sınıfta daha yetkin hissederler, gerekli görevleri daha anlamlı bulurlar ve öğrenme süreçleri üzerinde bir etkileri olduğu duygusu taşırlar (Frymier ve Houser, 1999; Houser ve Frymier, 2009: 35). Özetle öğrenen güçlenmesi, kişisel inisiyatif almay1, bir görevi tamamlamadaki sebatı ve öz yeterlilik duygularını arttıran bir dizi motivasyon sürecini ifade eder (Conger ve Kanungo, 1988).

\section{Araştırmanın Amacı ve Önemi}

$\mathrm{Bu}$ araştırmada Türkçe Öğretmenliği lisans programında yer alan Osmanlı Türkçesi dersine yönelik öğretmen adaylarının öğrenen güçlenme düzeylerinin cinsiyet ve sınıf değişkenleri açısından incelenmesi amaçlanmaktadır. Elde edilen verilerden hareketle öğretmen adaylarının Osmanlı Türkçesi dersine yönelik tutumlarına ilişkin verilere de ulaşılacaktır. Bu sayede, Türkçe öğretmenliği lisans programında öğrenim gören öğrencilerin en çok zorlandıkları derslerden biri olan Osmanlı Türkçesi dersine ilişkin değerlendirmeler yapılabilecektir. Ayrıca bu çalışma, "öğrenen güçlenmesi" kavramının ve bu kavrama ilişkin boyutların eğitimde uygulanmasına ilişkin literatüre katkı sağlayacaktır. 


\section{Yöntem}

\subsection{Araștırmanın Deseni}

Araştırma, "betimsel tarama modeli"ne göre yürütülmüştür. Tarama modelleri, geçmişte ya da hâlen var olan bir durumu var olduğu şekliyle betimlemeyi amaçlayan araştırma yaklaşımlardır. Tarama modellerinde araştırmaya konu olan olay, birey ya da nesne kendi koşulları içinde, herhangi bir değiştirme, etkileme çabası olmaksızın tanımlanmaya çalışılır (Karasar, 2015: 77).

\subsection{Katılımcilar}

Araştırma, 2017-2018 eğitim-öğretim yılının bahar döneminde Dicle Üniversitesi Ziya Gökalp Eğitim Fakültesi Türkçe Eğitimi Ana Bilim Dalı'nda öğrenim gören toplam 167 öğrencinin katılımı ile gerçekleştirilmiştir. Katılımcıların Türkçe Öğretmenliği lisans programında yer alan Osmanlı Türkçesi I ve Osmanlı Türkçesi II derslerini almış olmalarına dikkat edilmiştir. Katılımcılara ilişkin bilgiler Tablo 1'de yer almaktadır:

Tablo 1. Katılımcılara ilişkin bilgiler

\begin{tabular}{lccccc}
\hline & 1. Sinıf & 2. Sinıf & 3. Sinıf & 4. Sinıf & Toplam \\
\hline Kadın & 6 & 28 & 20 & 56 & 110 \\
Erkek & 9 & 10 & 8 & 30 & 57 \\
\hline Toplam & 15 & 38 & 28 & 86 & 167 \\
\hline
\end{tabular}

\subsection{Verilerin Toplanması ve Çözümlenmesi}

Araştırmada, katılımcıların Osmanlı Türkçesi dersine yönelik öğrenen güçlenmesi düzeylerinin belirlenmesi amacıyla Frymier, Shulman ve Houser (1996) tarafından geliştirilen, Çakır ve Erdoğan (2014) tarafından Türkçeye uyarlanan Öğrenen Güçlenmesi Ölçeği kullanılmıştır.

Öğrenen Güçlenmesi Ölçeği üniversite öğrencilerinin katıldıkları dersleri anlamlılık, yeterlilik ve etki boyutlarında değerlendirmeye olanak veren bir ölçektir. Ölçeğin orijinali (İngilizce formu), üniversite öğrencilerinin bir ders ortamında yaşadığı öğrenen güçlenmesi düzeyini anlamlılık, etki ve yeterlilik olmak üzere üç boyutlu olarak ölçmeyi amaçlayan 35 maddeden oluşmaktadır. Ölçeğin geçerlik ve güvenirlik çalışmaları sonucunda ilgili ölçek Türkçeye uyarlanarak 23 maddeye indirilmiştir. Ölçeğin 3 faktörlü bir yapıya sahip olduğu belirlenmiştir. Ölçeğin Türkçe formunda yer alan "etki" alt boyutunda 10 madde, "anlamlılık" alt boyutunda 7 madde ve "yeterlilik" alt boyutunda 6 madde yer almaktadır (Çakır ve Erdoğan, 2014).

Araştırmanın verileri, SPSS 21.0 veri analiz programı kullanılarak çözümlenmiştir. Değişkenlere ilişkin betimleyici istatistikler, bağımsız örneklem t testi ve tek yönlü varyans analizi (ANOVA) ile analiz edilmiştir.

\section{Bulgular ve Yorum}

Öğrenen Güçlenmesi Ölçeği'nin güvenirlik katsayısının belirlenmesi için ölçeğin tümünün ve alt boyutlarının Cronbach's Alpha değeri hesaplanmıștır. Buna göre 23 maddeden oluşan Öğrenen Güçlenmesi Ölçeği’ne ilişkin güvenirlik katsayısı ,957 olarak hesaplanmıştır. Ölçeğin alt boyutlarına ait güvenirlik katsayı değerleri Tablo 2'de sunulmuştur:

Tablo 2. Öğrenen Güçlenmesi Ölçeği’nin alt boyutlarına ait güvenirlik katsayıları

\begin{tabular}{lcc}
\hline Boyut Adı & İçerdiği Madde Sayısı & $\begin{array}{c}\text { Güvenirlik Katsayıs } \\
\text { (Cronbach's Alpha Değeri) }\end{array}$ \\
\hline "Etki" & 10 Madde &, 912 \\
"Anlamlılık" & 7 Madde &, 897 \\
"Yeterlilik" & 6 Madde &, 898 \\
\hline
\end{tabular}


Tablo 2'de görüldüğü gibi, on maddeden oluşan “etki” boyutunun güvenirlik katsayıs1 ,912; yedi maddeden oluşan "anlamlılık" boyutunun güvenirlik katsayıs1,897 ve altı maddeden oluşan "yeterlilik" boyutunun güvenirlik katsayısı ise ,898 olarak hesaplanmıştır. Bu değerler, ölçeğin tamamı ve alt boyutları için güvenirliğin oldukça yüksek olduğunu göstermektedir. Öğrenen Güçlenmesi Ölçeği'nde yer alan maddelere ait ortalamalar hesaplanmış, Tablo 3’te sunulmuştur:

Tablo 3. Öğrenen Güçlenmesi Ölçeği'nde yer alan maddelere ait ortalamalar

\begin{tabular}{|c|c|}
\hline "Etki" Boyutu & $\overline{\bar{X}}$ \\
\hline 1. Bu dersteki faaliyetlerin nasıl yapılacağını etkileme gücüm var. & 3,14 \\
\hline 2. Bu dersin başarısında benim katılımım önemlidir. & 3,18 \\
\hline 3. Bu dersteki işlerin yürütülme biçimini etkileyebilirim. & 3,04 \\
\hline 4. Bu derste diğer öğrencilerin öğrenmelerine katkıda bulunma fırsatım var. & 3,11 \\
\hline 5. Bu derste önemli kararların alınmasında bana da firsat tanınır. & 2,85 \\
\hline 6. Bu derste iyi bir öğrenme ortamı yaratma gücüne sahibim. & 3,07 \\
\hline 7. Faaliyetlerin nasıl yapılacağını belirleyebilirim. & 3,24 \\
\hline 8. Bu derste gerçekleşen öğrenme üzerinde bir fark yaratırım. & 3,11 \\
\hline 9. Öğretim elemanını (dersle ilgili konularda) etkileyebilirim. & 2,90 \\
\hline 10. Bu derste takdir edildiğimi hissediyorum. & 3,20 \\
\hline "Anlamlıl1k" Boyutu & $\bar{X}$ \\
\hline 11. Bu derste yerine getirmem gereken görevler benim için anlamlıdır. & 3,60 \\
\hline 12. Bu derse girmeyi dört gözle beklerim. & 2,79 \\
\hline 13. Bu ders zevklidir. & 3,08 \\
\hline 14. Bu ders ilgi çekicidir. & 3,01 \\
\hline 15. Bu derste yerine getirmem gereken görevler benim için değerlidir. & 3,35 \\
\hline 16. Bu dersteki bilgiler yararlıdır. & 3,56 \\
\hline 17. Bu ders, gelecekteki amaçlarıma ulaşmamda bana yardımcı olacaktır. & 3,22 \\
\hline "Yeterlilik" Boyutu & $\overline{\bar{X}}$ \\
\hline 18. Görevlerimi layıkıyla yerine getirebilme konusunda kendime güveniyorum. & 3,78 \\
\hline 19. Bu derste başarılı olmak için gerekli becerilere sahibim. & 3,57 \\
\hline 20. Bu dersteki amaçlarımı gerçekleştirecek yeterlilikte olduğuma inanıyorum. & 3,51 \\
\hline 21. Bu derste başarılı olmak için yeteneklerime güveniyorum. & 3,60 \\
\hline 22. Bu derste başarılı olmak için gerekli niteliklere sahibim. & 3,67 \\
\hline 23. Bu derste kendimi oldukça yeterli hissediyorum. & 3,32 \\
\hline
\end{tabular}

Tablo 3'teki "etki" boyutunda yer alan maddelere ait ortalama değerler incelendiğinde, öğretmen adaylarının Osmanlı Türkçesi dersinde yapacağı faaliyetleri belirleyebildiği ve derste takdir edildiği anlaşılmaktadır. Bunun yanında, öğrencilerin derste önemli kararlar alınmasında kendilerine firsat tanınmadığını ifade etmeleri ve öğretim elemanını dersle ilgili konularda etkileyemeyeceklerini düşünmeleri de dikkat çekici bir bulgudur.

"Anlamlılık" boyutuna ilişkin ortalamalar, öğretmen adaylarının Osmanlı Türkçesi dersinde edindikleri bilgileri ve yerine getirmeleri gereken görevleri anlamlı buldukları anlaşılmaktadır. Buna karşın, bulgulardan hareketle, öğrencilerin Osmanlı Türkçesi dersini çok ilgi çekici bulmadıkları ve derse girme motivasyonlarının yeterince yüksek olmadığı ifade edilebilir.

"Yeterlilik" boyutundaki bulgular incelendiğinde, bu boyuttaki ortalamaların diğer boyutlara göre daha yüksek olduğu görülmektedir. Elde edilen verilerden hareketle, öğrencilerin Osmanlı Türkçesi dersi ile ilgili görevleri layıkıyla yerine getirebilme konusunda kendilerine güvendikleri ve bu derste başarılı olmak için gerekli niteliklere sahip olduklarını düşündükleri sonucuna varılabilir. 
Türkçe öğretmeni adaylarının öğrenen güçlenmesi düzeylerinin cinsiyet değişkenine göre farklılaşıp farklılaşmadığı bağımsız örneklem t testi ile analiz edilmiş, analiz sonuçları Tablo 4'te sunulmuştur.

Tablo 4. Türkçe öğretmeni adaylarının öğrenen güçlenmesi düzeylerinin cinsiyet değişkenine göre analizi

\begin{tabular}{|c|c|c|c|c|c|c|}
\hline Boyut & Cinsiyet & $\mathrm{N}$ & Ortalama & Std. Sapma & $\mathrm{t}$ & $\mathrm{p}$ \\
\hline \multirow{2}{*}{ "Etki" } & Kadın & 114 & 3,3634 & ,93038 & \multirow{2}{*}{2,283} & \multirow{2}{*}{, 021} \\
\hline & Erkek & 53 & 2,9111 & 98179 & & \\
\hline \multirow{2}{*}{ "Anlamlılık" } & Kadın & 114 & 3,3634 & 1,09312 & \multirow{2}{*}{2,642} & \multirow{2}{*}{,011 } \\
\hline & Erkek & 53 & 2,9111 & 99930 & & \\
\hline \multirow{2}{*}{ "Yeterlilik" } & Kadın & 114 & 3,6988 & 1,01049 & \multirow{2}{*}{2,467} & \multirow{2}{*}{,014 } \\
\hline & Erkek & 53 & 3,2830 & 1,01515 & & \\
\hline
\end{tabular}

Tablo 4'teki bulgular 1şığında, cinsiyet değişkeni açısından öğretmen adaylarının öğrenen güçlenmesi düzeylerinin "etki", "anlamlılık" ve "yeterlilik" boyutlarına göre istatistiksel açıdan anlamlı düzeyde farklılık göstermediği belirlenmiştir ("Etki" boyutu $\mathrm{t}_{(, 93038-}$

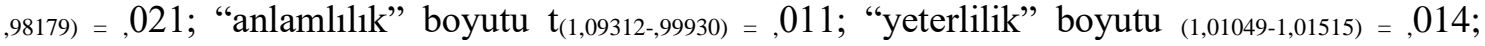
$\mathrm{p}>, 05)$. Bunun yanında, öğretmen adaylarının öğrenen güçlenme düzeylerini ifade eden ortalama değerlere bakıldığında, tüm boyutlarda kadın öğretmen adaylarının ortalamalarının erkek öğretmen adaylarına göre daha yüksek olduğu belirlenmiş̧tir.

Türkçe öğretmeni adaylarının öğrenen güçlenmesi düzeylerinin sınıf değişkenine göre farklılaşıp farklılaşmadığı tek yönlü varyans analizi (ANOVA) ile analiz edilmiş, ortalama ve standart sapma değerleri Tablo 5'te, analiz sonuçları ise Tablo 6'da sunulmuştur.

Tablo 5. Türkçe öğretmeni adaylarının öğrenen güçlenmesi düzeylerinin sınıf değişkenine göre ortalama ve standart sapma değerleri

\begin{tabular}{lcccc}
\hline Boyut & Sinıf & N & Ortalama & Std. Sapma \\
\hline \multirow{4}{*}{ "Etki" } & 1. Sinıf & 15 & 3,3600 & 2,8203 \\
& 2. Sinıf & 38 & 2,8842 & 2,5712 \\
& 3. Sinıf & 28 & 3,4036 & 3,0538 \\
& 4. Sinıf & 86 & 3,0058 & 2,8005 \\
& Toplam & 167 & 3,0845 &, 96197 \\
\hline \multirow{3}{*}{ "Anlaml1l1k" } & 1. Sinıf & 15 & 3,7619 & 3,1125 \\
& 2. Sinıf & 38 & 2,9323 & 2,5964 \\
& 3. Sinıf & 28 & 3,3622 & 2,9757 \\
& 4. Sinıf & 86 & 3,2060 & 2,9717 \\
"Yeterlilik" & Toplam & 167 & 3,2279 & 1,08383 \\
& 1. Sinıf & 15 & 3,8667 & 3,2204 \\
& 2. Sinıf & 38 & 3,3158 & 3,0254 \\
& 3. Sinıf & 28 & 3,6845 & 3,2994 \\
& 4. Sinıf & 86 & 3,5872 & 3,3588 \\
& Toplam & 167 & 3,5734 & 1,02784 \\
\hline
\end{tabular}


Tablo 6. Türkçe öğretmeni adaylarının öğrenen güçlenmesi düzeylerinin sınıf değişkenine göre tek yönlü varyans analizi (ANOVA) sonuçları

\begin{tabular}{|c|c|c|c|c|c|c|}
\hline Boyut & $\begin{array}{l}\text { Varyansın } \\
\text { Kaynağ } 1\end{array}$ & $\begin{array}{l}\text { Kareler } \\
\text { Toplamı }\end{array}$ & $\begin{array}{c}\text { Kareler } \\
\text { Ortalaması }\end{array}$ & $\mathrm{Sd}$ & $\mathrm{F}$ & $\mathrm{p}$ \\
\hline \multirow{3}{*}{ “Etki” } & $\begin{array}{l}\text { Gruplar } \\
\text { Aras1 }\end{array}$ & 7,776 & 1,944 & 4 & \multirow{3}{*}{2,159} & \multirow{3}{*}{, 076} \\
\hline & $\begin{array}{l}\text { Gruplar } \\
\text { İçi }\end{array}$ & 146,763 & ,900 & 163 & & \\
\hline & Toplam & 154,540 & & 167 & & \\
\hline \multirow[b]{2}{*}{ "Anlamlıllk" } & $\begin{array}{l}\text { Gruplar } \\
\text { Aras1 }\end{array}$ & 9,949 & 2,487 & 4 & \multirow[b]{2}{*}{2,177} & \multirow[b]{2}{*}{, 074} \\
\hline & $\begin{array}{l}\text { Gruplar } \\
\text { İçi } \\
\text { Toplam }\end{array}$ & $\begin{array}{l}186,224 \\
196,173\end{array}$ & 1,142 & 163 & & \\
\hline \multirow[b]{2}{*}{ "Yeterlilik" } & $\begin{array}{l}\text { Toplam } \\
\text { Gruplar } \\
\text { Aras1 }\end{array}$ & $\begin{array}{c}196,173 \\
5,369\end{array}$ & 1,342 & $\frac{167}{4}$ & \multirow[b]{2}{*}{1,279} & \multirow[b]{2}{*}{,280 } \\
\hline & $\begin{array}{l}\text { Gruplar } \\
\text { İçi } \\
\text { Toplam }\end{array}$ & $\begin{array}{l}171,059 \\
176,428\end{array}$ & 1,049 & $\begin{array}{l}163 \\
167\end{array}$ & & \\
\hline
\end{tabular}

Tablo 5 ve Tablo 6'da, Türkçe öğretmeni adaylarının öğrenen güçlenmesi düzeyleri sınıf değişkenine göre incelenmiştir. Elde edilen bulgular sonucunda, sınıf değişkeni açısından öğretmen adaylarının öğrenen güçlenmesi düzeylerinin "etki", "anlamlılık" ve "yeterlilik" boyutlarına göre istatistiksel açıdan anlamlı düzeyde farklılık göstermediği belirlenmiştir ("Etki" boyutu $\mathrm{F}_{(4-163)}=2,159, \mathrm{p}>, 05$; "anlaml111k" boyutu $\mathrm{F}_{(4-163)}=2,177, \mathrm{p}>, 05$; "yeterlilik" boyutu $\left.\quad \mathrm{F}_{(4-163)}=1,279, \mathrm{p}>, 05\right)$.

\section{Sonuç ve Öneriler}

Araştırma sonucunda, cinsiyet ve sınıf değişkenleri açısından öğretmen adaylarının öğrenen güçlenmesi düzeylerinin "etki", "anlamlılık" ve "yeterlilik" boyutlarına göre istatistiksel açıdan anlamlı düzeyde farkl11ık göstermediği belirlenmiştir. Bunun yanında, öğretmen adaylarının öğrenen güçlenme düzeylerini ifade eden ortalama değerlere bakıldığında, tüm boyutlarda kadın öğretmen adaylarının ortalamalarının erkek öğretmen adaylarına göre daha yüksek olduğu ortaya konmuştur.

Elde edilen bulgular sonucunda Türkçe öğretmeni adaylarının Osmanlı Türkçesi dersine ait tutumları ve deneyimlerine ilişkin bazı verilere ulaşılmıştır. Buna göre Türkçe öğretmeni adaylarının;

- Osmanlı Türkçesi dersinde yapacakları faaliyetleri belirleyebildiği ve derste takdir edildikleri,

- Osmanlı Türkçesi dersinde edindikleri bilgileri ve yerine getirmeleri gereken görevleri anlamlı buldukları,

- Osmanlı Türkçesi dersi ile ilgili görevleri layıkıyla yerine getirebilme konusunda kendilerine güvendikleri,

- $\mathrm{Bu}$ derste başarılı olmak için gerekli niteliklere sahip olduklarını düşündükleri sonucuna ulaşılmıştır.

Buna karşın verilerden hareketle, Türkçe öğretmeni adaylarının;

- derste önemli kararlar alınmasında kendilerine firsat tanınmadığını ve öğretim elemanını dersle ilgili konularda etkileyemeyeceklerini düşündükleri,

- Osmanlı Türkçesi dersini çok ilgi çekici bulmadıkları,

- derse girme motivasyonlarının yeterince yüksek olmadığı ifade edilebilir. 
Araştırmada ulaşılan veriler, literatürdeki ilgili çalışmalarla (Brooks ve Young, 2011; Guay, Vallerand ve Blanchard, 2000; Frymier ve diğ., 1996) aynı doğrultudadır. Bu çalışmalarda, motivasyon ve öğrenen güçlenmesi düzeyleri arasında güçlü bir ilişki olduğunu ifade edilmektedir. Türkçe öğretmeni adaylarının öğrenen güçlenmesi düzeylerini ifade eden maddelere ilişkin ortalama değerlere bakıldığında "anlamlılık" boyutunda en düşük ortalamaya sahip maddelerin sırasıyla "Bu derse girmeyi dört gözle beklerim" ve "Bu ders ilgi çekicidir" maddeleri olduğu görülmektedir. Bu bağlamda, öğrencilerin derse girme motivasyonlarının düşük olduğunda öğrenen güçlenme düzeylerinin de düştüğü ifade edilebilir.

Osmanlı Türkçesi dersinin "kültürü tanıma, Osmanlı Türkçesi ile yazılmış olan eserleri koruma konusunda hassasiyet kazanma, alana özgü çalışmalarda Osmanlı Türkçesi ile yazılmış eserlerden yararlanma" gibi amaçları olduğu söylenebilir (Çalışkan, 2013). Bu bağlamda, çalışmada öğrencilerin bu derse ilişkin görev ve sorumluluklarını anlamlı bulmaları da dersin amacının öğrenciler tarafından kavranmış olduğunu göstermesi açısından önem taşımaktadır.

Bundan sonra yapılacak çalışmalarda,

- Gerek Türkçe Öğretmenliği lisans programında gerekse diğer lisans programlarında yer alan derslere ilişkin öğretmen adaylarının öğrenen güçlenme düzeylerinin belirlenmesi önem taşımaktadır. Böylelikle ilgili derslere ait eğitim-öğretim uygulamalarına ilişkin dönütlerin alınması sağlanabilir ve bu dönütler öğretim elemanlarının dersi planlamalarına katkı sağlayabilir.

- Farklı bölümlerdeki öğretmen adaylarının öğrenen güçlenme düzeyleri karşılaştırılarak bölümlerde okuyan öğrencilere ve ilgili derslere yönelik çıkarımlarda bulunulabilir.

- Aynı bölümde okuyan öğrencilerin sınıf, cinsiyet gibi değişkenlerle öğrenen güçlenme düzeyleri arasında fark olup olmadığı değerlendirilebilir.

- Elde edilecek verilerden yararlanılarak ilgili derslere ve derse giren öğretim elemanlarına yönelik öğrencilerin olumsuz tutumlarının nedenlerinin araştırılması, sonraki dönemlerde bu derslerin verimliliğinin artmasına olumlu etki edebilir.

- Öğrenen güçlenme düzeyine ilişkin yurt içi ve dışında yapılmış çalışmalarla ilgili meta analiz çalışmaları yapılabilir. Böylece eğitimde öğrenen güçlenmesinin etkileri daha ayrıntılı biçimde ortaya konabilir.

- Öğrencilerin öğrenen güçlenme düzeylerinin tespit edilmesinin ardından ilgili düzeylerin nasıl geliştirilebileceğine ilişkin öğrencilere sorular sorularak literatür gelişimine katkıda bulunulabilir.

- Osmanlı Türkçesi dersinin öğrencilerin daha fazla ilgisini çekebilmesi için ders içerisinde görsel ve işitsel özgün materyallerden yararlanılabilir. Böylelikle ögrencilerin derse olan motivasyonları da arttırılabilir.

\section{Kaynakça}

Block, P. (1987). The Enpowered Manager: Positive Political Skills at Work. San Francisco: Jossey-Bass.

Brooks, F. C. ve Young, S. L. (2001). Are Choice-Making Opportunities Needed in The Classroom? Using Self-Determination Theory to Consider Student Motivation and Learner Empowerment. International Journal of Teaching and Learning in Higher Education, 23(1): 48-59. 
Conger, J. ve Kanungo, R. (1988). The Empowerment Process: Integrating Theory and Practice. Academy of Management Review, 13: 471-482.

Çakır, S. G. ve Erdoğan, M. (2014). "Öğrenen Güçlenmesi Ölçeğinin Uyarlanması: Geçerlik ve Güvenirlik Çalışmaları”, Mustafa Kemal Üniversitesi Sosyal Bilimler Enstitüsü Dergisi, 11(25): 297-307.

Çalışkan, N. (2013). Lise Düzeyindeki Osmanlı Türkçesi Dersi Öğretim Programı’nın Uygulanışına İlişkin Öğrenci Görüşlerine Dayalı Bir Değerlendirme, Bartın Üniversitesi Eğitim Fakültesi Dergisi, 2(2): 329-343.

Frymier, A. B. ve Houser, M. L. (1999). The Revised Learning Indicators Scale. Communication Studies, 50(1): 1-12.

Frymier, A. B., Shulman, G. M. ve Houser, M. (1996). The Development of a Learner Empowerment Measure. Communication Education, 45: 181-199.

Guay, F., Vallerand, R. J. ve Blanchard, C. (2000). On the Assessment of Situational Intrinsic and Extrinsic Motivation: The Situational Motivation Scale (SIMS). Motivation and Emotion, 24(3): 175-213.

Houser, M. L. ve Frymier, A. B. (2009). The Role of Student Characteristics and Teacher Behaviors in Students' Learner Empowerment, Communication Education, 58(1): 35-53.

Luechauer, D. ve Shulman, G. M. (1993). Empowerment at Work: Separating Folklore from Fact". At Work: Stories of Tomorrow's Workplace, 2(6): 13-14.

Schrodt, P., Witt, P. L., Myers, S. A., Turman, P. D., Barton, M. H. ve Jernberg, K. A. (2008). Learner Empowerment and Teacher Evaluations as Functions of Teacher Power Use in the College Classroom. Communication Education, 57(2): 180-200.

Senge, P. (1990). The Fifth Dicipline: The Art and Practice of Learning Organizations. New York: Currency Doubleday.

Thomas, K., ve Velthouse, B. (1990). Cognitive Elements of Empowerment: An Interpretive Model of Intrinsic Task Motivation. Academy of Management Review, 15: 666-681.

Weber, K. ve Patterson, B. R. (2000). Student Interest, Empowerment and Motivation. Communication Research Reports, 17: 22-29.

Zimmerman, M. A. (1990). Toward a Theory of Learned Hopefulness: A Structural Model Analysis of Participation and Empowerment. Journal of Research in Personality, 24: 71-86. 